\title{
Médiévales
}

Langues, Textes, Histoire

68 | printemps 2015

Langues d'Angleterre

\section{Martin NEJEDLÝ, Středověký mýtus o Meluzíně a rodová pověst Lucemburků [Le mythe médiéval de Mélusine et la légende familiale des Luxembourg]}

Prague, Scriptorium, 2014, 532 p., résumés anglais et français

Nicolas Richard

\section{CpenEdition}

\section{Journals}

Édition électronique

URL : https://journals.openedition.org/medievales/7523

DOI : 10.4000/medievales.7523

ISSN : $1777-5892$

\section{Éditeur}

Presses universitaires de Vincennes

Édition imprimée

Date de publication : 15 juin 2015

Pagination : 201-202

ISBN : 978-2-84292-430-0

ISSN : 0751-2708

\section{Référence électronique}

Nicolas Richard, « Martin NEJEDLÝ, Středověký mýtus o Meluzíně a rodová pověst Lucemburků [Le mythe médiéval de Mélusine et la légende familiale des Luxembourg] », Médiévales [En ligne], 68 | printemps 2015, mis en ligne le 27 juillet 2015, consulté le 23 avril 2022. URL : http://journals.openedition.org/ medievales/7523; DOI : https://doi.org/10.4000/medievales.7523

Ce document a été généré automatiquement le 23 avril 2022

Tous droits réservés 


\title{
Martin NEJEDLÝ, Středověký mýtus o Meluzíně a rodová pověst Lucemburků [Le mythe médiéval de Mélusine et la légende familiale des Luxembourg]
}

Prague, Scriptorium, 2014, 532 p., résumés anglais et français

\author{
Nicolas Richard
}

\section{RÉFÉRENCE}

Martin NEJEDLÝ, Středověký mýtus o Meluzíně a rodová pověst Lucemburků [Le mythe médiéval de Mélusine et la légende familiale des Luxembourg], Prague, Scriptorium, 2014, 532 p., résumés anglais et français.

1 Martin Nejedlý, maître de conférences habilité à l'Université Charles de Prague, réédite avec cet ouvrage son livre paru sous le même titre en 2007. Il le met à jour et y ajoute de substantiels passages, notamment à propos du roman de Jean d'Arras. Comme aucun compte rendu de cet important ouvrage n'était paru dans ces colonnes, nous saisissons l'occasion de sa réédition pour revenir ici sur le livre dans son entier.

En bon disciple de feu Jacques Le Goff, Martin Nejedlý est obsédé par la question de la source, posée dès le premier chapitre : comment l'historien doit-il user de la littérature féérique médiévale ? Elle n'a pas moins à être prise en compte que les autres documents historiques. La laisser aux littéraires n'est pas satisfaisant, non plus qu'un dépeçage qui ne garderait du texte que ce qu'en jugerait utilisable une arbitraire "vraisemblance ». Les onze chapitres suivants, portant chacun le nom d'une fleur symbolisant pour Froissart un sentiment humain, sont pour l'auteur autant d'occasions de donner une leçon de méthode en la matière. Martin Nejedlý commence par débrouiller la situation politique passablement complexe du règne de Charles VI dans laquelle se meut Jean d'Arras, lorsqu'il achève pour le duc de Berry, sa sœur Marie de Bar et le margrave de 
Moravie Jost (Josse de Luxembourg), son roman sur Mélusine, dont tous trois prétendent être les descendants (1393). En faisant le lien entre le mécénat du duc de Berry et ses ambitions politiques, Martin Nejedlý en vient, au chapitre suivant, au problème largement insoluble et en partie vain des origines du mythe de Mélusine : si l'apparition en 1373 du serpent Mélusine au gouverneur anglais du château de Lusignan est bien connue, de même que les sources utilisées par Jean d'Arras, le mythe, lui, plonge ses origines dans l'inconnu, ce que Martin Nejedlý illustre à partir de données folkloriques extra-européennes et d'époques diverses. L'image de la fée dans la littérature, à laquelle l'auteur consacre le chapitre qui suit, n'en est pas moins très diverse. Martin Nejedlý passe en revue les différentes explications du phénomène de la littérature féérique dans la société médiévale (ses rapports avec l'Église, la religion, la magie, l'inconscient, la noblesse, etc.) et en arrive à la conclusion qu'il n'existe pas de réponse univoque : la place sociale de ce genre littéraire varie sur des échelles de valeur elles-mêmes diverses. C'est aussi le cas de la figure même de la fée, étudiée au chapitre V qui, comme les précédents, fait la plus large part à toutes les œuvres de la littérature médiévale féérique (comme la matière du Graal), ce qui permet à Martin Nejedlý de faire connaître au public tchèque avec une inépuisable érudition un éventail de sources en partie inconnues dans la Bohême médiévale, mais où le roman de Mélusine prend sa source.

Le chapitre VI en revient à la légende de Mélusine elle-même. L'auteur montre comment, dans le contexte de souffrances et de doutes du XIV ${ }^{\mathrm{e}}$ siècle, la présence d'une fée dans un lignage en rehaussait le prestige, car les Lusignan - et par eux, les Luxembourg - n'étaient pas les seuls à favoriser le développement de tels mythes. Le moment est revenu de s'interroger sur l'efficacité politique de tels textes. À rebours d'un certain dédain pour les romans de chevalerie, Martin Nejedlý montre comment ceux-ci façonnent des comportements politiques, asseyent des légitimités dans un passé immémorial, etc. Leur juste interprétation comme source historique ne peut se faire qu'en étroite collaboration avec les historiens de la littérature et ceux des autres périodes, collaboration qui est la seule voie pour faire sortir l'histoire politique de l'accumulation de faits et lui permettre de pénétrer dans la culture et l'imaginaire politique médiéval. Ces vues neuves ouvrent de nouvelles perspectives à l'étude politique des sources littéraires de l'époque des Luxembourg rois de Bohême. Martin Nejedlý les double d'une étude des représentations figurées de Mélusine et de l'évolution de celles-ci, en particulier comme meuble héraldique. L'ouvrage apporte ainsi une contribution majeure à l'histoire de la représentation figurée de Mélusine dans la Bohême du XIV ${ }^{\mathrm{e}}$ siècle, sur les fresques, les dalles de pavement, etc. Mélusine illustre aussi les livres : avec les débuts de l'imprimé, on passe d'une figuration proche du texte, axée sur le caractère miraculeux de la transformation de Mélusine en dragon, à une représentation plus autonome, où l'humanisation et l'expression des sentiments vont de pair. Les illustrations sont le moyen de repérer l'influence, en Bohême, de la légende familiale des souverains dont la fortune littéraire fut fort mince avant une époque tardive. La chose n'empêche pas le lien étroit entre la légende de la fée et les croisades, autre élément-clé pour le prestige de la famille des Luxembourg : «Lusignans de Bohême ", ils faisaient ainsi jouer à la fois l'héritage des rois de chypre et de Jérusalem, et les exploits contre les infidèles des fils de Mélusine, tels que Jean d'Arras les raconte complaisamment (chap. IX). La question de la date de l'introduction de la légende de Mélusine à la cour de Prague reste ouverte, mais le roman de Jean d'Arras présente une vision de la Bohême que Martin Nejedlý compare avec celle des autres 
auteurs français qui appartiennent à ce vaste courant d'intérêt pour les pays tchèques ; contrairement aux descriptions "plus réalistes ", mais répondant à d'autres critères littéraires, l'ouvrage montre le royaume comme partie de la civilisation chrétienne, et cette vision particulièrement positive sert les intérêts conjoints des Luxembourg et des Valois. L'idée de fécondité et de succès que possède le lignage de la fée sert les intérêts de ses descendants en Bohême, mais les échecs accumulés par la famille, les désastres essuyés par la chevalerie chrétienne contre les Turcs, amènent à l'autonomisation de la légende, dont Martin Nejedlý analyse l'évolution aux époques suivantes (chap. XI-XII). Cette étude sur le sujet mélusinien dans la littérature et le folklore tchèques entre le $\mathrm{xv}^{\mathrm{e}}$ et le $\mathrm{XXI}^{\mathrm{e}}$ siècle clôt le livre.

4 Il est certain qu'un tel ouvrage, écrit en tchèque pour des lecteurs tchèques, a constitué dès sa parution à Prague une pierre miliaire, tant pour sa méthode novatrice que pour le chantier neuf qu'il ouvre dans un pan de l'histoire médiévale du pays. Le lecteur français, sensible certes à la profondeur impressionnante de l'érudition que possède Martin Nejedlý des sources et des historiens français, trouvera surtout dans ce livre une histoire neuve des liens entre la cour des Valois et celle de Prague à la fin du XIV siècle, en matière politique et culturelle. In fine, le mythe de Mélusine est l'exemple achevé d'un transfert culturel réussi.

5 Autant dire que ce livre, qui est lui-même un bel objet, dont on aimerait que les éditeurs français aient les moyens de s'inspirer (illustrations de qualité, reliure solide, composition en cahiers, typographie impeccable, relecture soignée), apporte bien plus que ne laisse espérer le simple titre: Le Mythe de Mélusine et la légende familiale des Luxembourg.

\section{AUTEURS}

NICOLAS RICHARD

Fondation Thiers, CNRS 